\title{
Ocular Microbiota and Intraocular Inflammation
}

\author{
Jing Jing $L i^{*}$, Sanjun Yi and Lai Wei* \\ State Key Laboratory of Ophthalmology, Zhongshan Ophthalmic Center, Sun Yat-sen University, Guangzhou, China
}

The term ocular microbiota refers to all types of commensal and pathogenic microorganisms present on or in the eye. The ocular surface is continuously exposed to the environment and harbors various commensals. Commensal microbes have been demonstrated to regulate host metabolism, development of immune system, and host defense against pathogen invasion. An unbalanced microbiota could lead to pathogenic microbial overgrowth and cause local or systemic inflammation. The specific antigens that irritate the deleterious immune responses in various inflammatory eye diseases remain obscure, while recent evidence implies a microbial etiology of these illnesses. The purpose

OPEN ACCESS

Edited by:

Peizeng Yang,

First Affiliated Hospital of Chongqing

Medical University, China

Reviewed by:

Uma Sriram,

Temple University, United States

Seung-Hyo Lee,

Korea Advanced Institute of Science and Technology, South Korea

${ }^{*}$ Correspondence:

Jing Jing $\mathrm{Li}$ lijingjing@gzzoc.com

Lai Wei

weil9@mail.sysu.edu.cn

Specialty section: This article was submitted to

Autoimmune and

Autoinflammatory Disorders,

a section of the journal

Frontiers in Immunology

Received: 24 September 2020 Accepted: 23 November 2020 Published: 23 December 2020

Citation:

Li JJ, Yi S and Wei L (2020) Ocular Microbiota and Intraocular Inflammation.

Front. Immunol. 11:609765.

do: 10.3389/fimmu.2020.609765 of this review is to provide an overview of the literature on ocular microbiota and the role of commensal microbes in several eye diseases. In addition, this review will also discuss the interaction between microbial pathogens and host factors involved in intraocular inflammation, and evaluate therapeutic potential of targeting ocular microbiota to treat intraocular inflammation.

Keywords: ocular microbiota, ocular surface microbiome, intraocular inflammation, eye, ocular inflammatory disease

\section{INTRODUCTION}

As the term microbiota refers to all types of microorganisms present in or on human body, the term ocular microbiota refers to all types of microorganisms present in or on the eyes. Ever since the launch of the Human Microbiome Project, our understanding toward the diversity and composition of commensal microbiota has been expanding. It has been evidenced that commensal microbiota plays fundamental roles in regulating host physiology, induction and development of immune

\footnotetext{
Abbreviations: AMD, age-related macular degeneration; DR, diabetic retinopathy; CNS, central nervous system; RGC, retinal ganglion cell; BD, Behcet's disease; rRNA, ribosomal RNA; ITS, internal transcribed spacer; PMNs, polymorphonuclear leukocytes; ACAID, anterior chamber-associated immune deviation; cfu, colony-forming unit; HLA-B27, human leukocyte antigen-B27; MHC, major histocompatability complex; EAU, experimental autoimmune uveitis; IRBP, interphotoreceptor retinoid binding protein; TCR, T cell receptor; CF, complement factor H; ARMS2, age-related maculopathy susceptibility 2; TIMP3, tissue inhibitor of metalloproteinases-3; MMP9, matrix metallopeptidase 9; APOE, apolipoprotein E; LIPC, lipase C; CETP, cholesteryl ester transfer protein; ABCA1, ATP-binding cassette transporter; RPE, retinal pigment epithelium; LPS, lipopolysaccharide; TLR, Toll-like receptor; PAMP, pathogen-associated molecular pattern; DAMP, damage-associated molecular pattern; APC, antigen presenting cells; PRR, pattern recognition receptors; TIR, Toll/IL-1 receptor; MyD88, Myeloid differentiating factor 88; TRIF, TIR domain containing adaptor inducing interferon $\beta$; TIRAP, TIR domaincontaining adaptor protein; TRAM, TRIF-related adaptor molecule; IRF, interferon regulatory factor; MAPK, mitogenactivate protein kinase; AAU, acute anterior uveitis; DC, dendritic cells; VCAM-1, vascular cell adhesion molecule-1; ICAM-1, intercellular cell adhesion molecule-1; MIP, macrophage inflammatory protein; MCP-1, monocyte chemotactic protein-1.
} 
system, as well as host defense against pathogen invasion, albeit dysbiosis (unbalanced microbiota) could lead to pathogenic microbial overgrowth and cause local or systemic inflammation (1). The ocular surface is directly exposed to the external environment and endangered by various pathogenic microorganisms. These facts combined with our recent findings of intraocular microbes raise intense research interest in clarifying the role of ocular microbiota in ocular health and diseases.

The ocular immune system is composed of a complex network of innate and adaptive components. Infection or autoimmunity could lead to intraocular inflammation which is associated with a multitude of sight-threatening diseases, which include but may not be limited to endophthalmitis, uveitis, agerelated macular degeneration (AMD), glaucoma, and diabetic retinopathy (DR). Intraocular inflammation exerts deleterious effects on vision integrity since the delicate ocular components, such as the retina and the cornea, are unable to regenerate. The eye is an immunologically privileged organ. Up to date, the specific antigens that irritate the deleterious immune responses in the immune privileged site in those diseases remain obscure. A growing body of research has shown that commensal microbes might be the trigger of intraocular inflammation. Here, we discuss evidence for the relationship between microbes and ocular diseases, discuss microbial pathogen and host factors, including the molecular and cellular interactions, involved in non-infectious intraocular inflammation, and evaluate therapeutic potential of targeting ocular microbiota to treat intraocular inflammation.

\section{THE OCULAR MICROBIOTA}

The ocular surface is the interface between the eye and the environment which comprises the cornea, the conjunctiva, the tear film, and the eyelids. It has been much debated whether the microorganisms in our environment are able to adhere to and colonize the ocular surface, because during eye blinking, tears secreted from the lacrimal gland of the eyes contain lysozyme that could kill bacteria and wash the ocular surface (1). Supporting evidence for the existence of ocular surface microorganisms arises from microbial cultivation studies documented first in 1930 (2). Many subsequent results from similar studies are in line with the first discovery. Swabs from different parts of the ocular surface were incubated in bacteria growth media (mostly blood and chocolate agar). The incubations occur in aerobic, anaerobic, or $5 \% \mathrm{CO}_{2}$ for up to 14 days at body temperature (3). These culture-based methods are invaluable in a historical perspective in confirming the existence of a microbiota and identifying microorganisms. The common bacteria isolated from these sites of the eye are Grampositive genera, including coagulase-negative Staphylococcus, Streptococcus, Propionibacterium, Diphtheroid bacteria and Micrococcus (4). Some genera that are abundant in the gut flora, such as Escherichia, Enterococcus, Lactobacillus, and Bacillus are less common on the normal ocular surface (4). Gram-negative genera, such as Haemophilus, Neisseria, Pseudomonas, and fungal isolates are even rarer but can also be isolated and cultured from the surface of eyes without obvious signs of inflammation or infection $(4,5)$. The most common ocular surface bacteria are coagulase-negative Staphylococci which present in $20-80 \%$ of the swabs from the conjunctiva and $30-100 \%$ of the swabs from the lids (4). The density of microbes recovered are usually lowest from tears while higher from conjunctiva and eye lid (3). Types of the ocular surface microbes identified are consistent with results from studies of cultivable microbiota from contact lenses, which also suggest that coagulase-negative Staphylococcus is the most common genera, and less commonly Bacillus, Micrococcus, and fungi (3).

The ocular surface and the sclera enwrap the interior ocular cavity. The cavity enclosed by the ocular outer compartments mainly consists of the anterior chamber, the posterior chamber, the ciliary body, and the vitreous body (Figure 1). Historically, the intraocular environment has been deemed sterile on account of its closed anatomical structure as well as protection provided

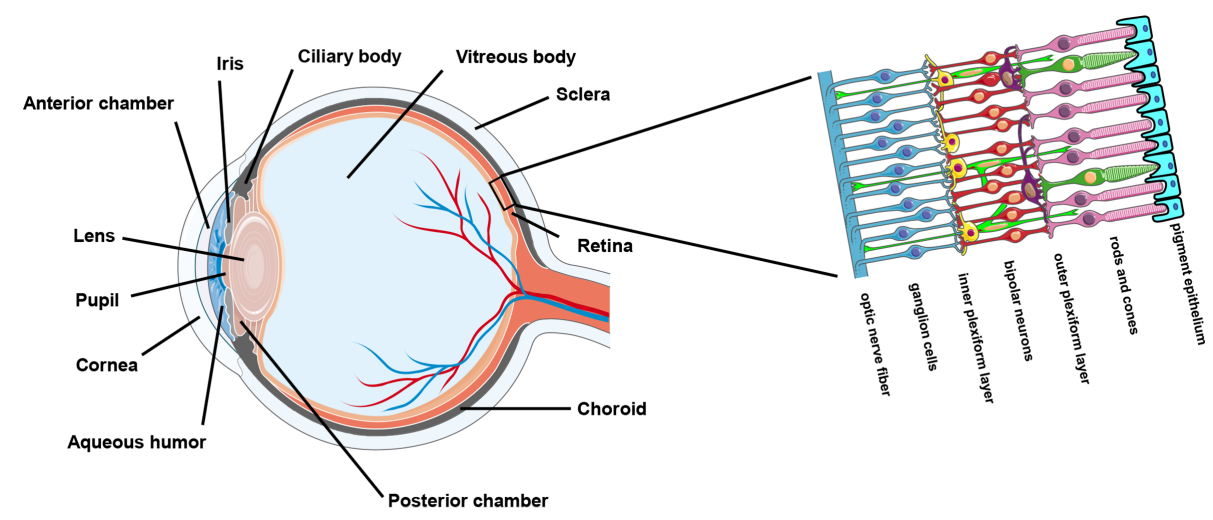

FIGURE 1 | Anatomy of the eye. 
by the tight and restrictive blood-retina barrier unless it is invaded by pathogens due to unnatural circumstances. Contamination could occur when the outer ocular compartments are damaged during an intraocular surgical procedure or following an injury caused by a penetrating foreign object $(6,7)$. For example, post-operative infectious endophthalmitis is a rare but serious vision-threatening complication of ocular surgery (e.g., cataract extraction) which involves inflammation of both the anterior and posterior segments of the eye. Post-operative endophthalmitis is presumably attributed to the diffusion of microorganisms from the patient's conjunctival or skin flora into the sterile intraocular compartments of the eye during surgery and cause overwhelming inflammation (8). Besides, diseased conditions that are associated with retinal vascular lesions could introduce microbial invasions from the circulating blood as normal human blood contains appreciable numbers of microorganisms (9-12). For example, one of the early pathological features of DR, a common diabetes complication in the eye, is retinal vascular leakage (13). Coincidently, DR has been demonstrated to be affected by microbiome $(14,15)$. Furthermore, some microbes (mainly viruses) could spread along the nerves. Cases of infections occurred in the central nervous system (CNS) by neurological spread are not sparse. Ocular infection could be secondary to a CNS infection. For instance, it has been reported that rabies virus infected in the hind limbs of mice could travel along the peripheral nerve and the axon to the brain and then spread to the eye through the optic nerve where it infects the retinal ganglion cell (RGC) but not the photoreceptors (16).

The vitreous humor and aqueous humor contain a variety of organic and anorganic components that form an excellent cultivating medium for microorganisms $(17,18)$. In the late 19th century, researchers found that microorganisms, such as Bacillus Subtilis and Bacillus Megaterium grew extremely well in the aqueous humor withdrawn from living body (18). In some studies by others, Propionibacterium acnes (P. acnes) was detected in the granuloma of the retina in patients with ocular sarcoidosis where accumulated $\mathrm{CD}^{+}$cells and $\mathrm{CD}^{+} 8^{+}$cells were also nearby, suggesting that $P$. acnes could be associated with sarcoid uveitis $(19,20)$. In line with their findings, we were able to detect the expression of $P$. acnes mRNA in most aqueous humor specimens we collected from patients undergoing cataract surgeries who were free of active or history of intraocular inflammation and infection, raising the question of whether $P$. acnes is a benign resident or a pathogenic intraocular microorganism and whether there is a community of microorganisms living inside the human eye. So far, there is no direct documentation of the existence of intraocular microbiome. This is possibly because the intraocular materials from healthy human eye are difficult to acquire. In our preliminary study, the intraocular microbial communities were significantly different among patients with distinct ocular diseases. Whether the intraocular microbiome lives in symbiosis with the host just as the intestinal microbiome and whether alteration of intraocular microbiome contributes to the ocular health and the etiology of ocular diseases in general remain to be examined.

\section{DEFINING THE OCULAR MICROBIOTA}

Methods to define a microbiota can be generally divided into culture-based techniques and non-culture-based techniques. The culture-based techniques depend on phenotypic characteristics of microbes to estimate the microbial load, for example, the ability of microbes in a sample to proliferate in or on a specified growth medium under a specified growth condition $(21,22)$. Although it provides a rough evaluation of microbial density and diversity in specimens, these measures are often inaccurate and biased. The cultivable species may only represent a small proportion of the real microbial populations in the samples which are prone to grow under the applied cultivation conditions $(23,24)$. In addition, the estimation of microbial density in a certain sample also varies according to a wide range of factors that may affect the proliferation ability of microbes. Some microbes are even uncultivable on traditional laboratory medium. Currently, only half of the bacterial phyla have cultivated representatives (25). Indeed, variations in types and density of microorganisms that can be cultured from the ocular surface exist in many published studies $(23,26)$.

The more advanced non-culture diagnostic methods are immunoassays, which target microbe-secreted peptides or microbial antigen, and metagenomic sequencing, which target microbial RNA or DNA. Both methods allow study of the community of the microbes present without obtaining pure cultures. Methods targeting microbial nucleic acids do not require specific antibodies making them more readily available for laboratory study. $16 \mathrm{~S}$ ribosomal RNA (rRNA) is commonly used for taxonomic purposes for bacteria, while 18S rRNA and internal transcribed spacer (ITS) are used for fungi. To define microbial species, the $16 \mathrm{~S} / 18 \mathrm{~S} / \mathrm{ITS}$ gene amplicons are usually sequenced and the sequence will be matched with the repository of existing sequence to yield taxonomic information. Nowadays, more than 9,000 16S rRNA gene sequences have been deposited in GenBank, rendering $16 \mathrm{~S}$ rRNA gene sequence analysis a better tool to identify those rarely isolated, poorly described, and uncultivable bacteria (27). Another sequencing method called shotgun metagenomics can achieve species- and strain-level resolution. It examines the entire genome as opposed to only the 16S/18S/ITS amplicons, but its high costs and heavy demands on bioinformatic analyses precluded its extensive use for microbiome study (28).

The first high-throughput study to explore the diversity of healthy human ocular surface microbiome was published in 2007 by Graham et al. in which they identified Staphylococcus, Rhodococcus, Corynebacterium, Propionibacterium, Klebsiella, Bacillus, and Erwinia as the main bacterial genera on healthy human ocular surface (2). However, the composition of the "core ocular surface microbiota" has been highly contested. Dong et al. proposed that 12 genera-Pseudomonas, Propionibacterium, Bradyrhizobium, Corynebacterium, Acinetobacter, Brevundimonas, Staphylococcus, Aquabacterium, Sphingomonas, Streptococcus, Streptophyta, and Methylobacterium-represented the putative "core" of conjunctival microbiota (29). Another study claimed that Corynebacterium, Streptococcus, Propionibacterium, Bacillus, 
Staphylococcus, and Ralsontia were detected in $80 \%$ of the 105 samples tested and together accounted for more than a third of the entire bacterial community characterized (30). The core conjunctival microbial communities were later shown to be composed of Corynebacterium, Pseudomonas, Staphylococcus, Acinetobacter, Streptococcus, Millisia, Anaerococcus, Finegoldia, Simonsiella, and Veillonella (31). Doan et al. applied three different techniques to explore the healthy human conjunctiva microbiome: bacterial culture, $16 \mathrm{~S}$ rDNA gene deep sequencing, and biome representational in silico karyotyping. They found that Corynebacteria, Propionibacterium, and coagulase-negative Staphylococcus were the predominant organisms (32). A study by Ozkan et al. reported that Corynebacterium, Acinetobacteria, Pseudomonas, Sphingomonas, Streptococcus, Massilia, and Rothia accounted for $80 \%$ of the operational taxanomic units (OTUs) and microbial genera on the ocular surface (24). The metagenomic data collected from our laboratory revealed that Propionibacterium, Staphylococcus, Escherichia, and Micrococcus were the most abundant ocular surface microbial genera in healthy humans (33). Li et al. found the predominant genera to be Pseudomonas, Acinetobacter, Bacillus, Chryseobacterium, and Corynebacterium (34). The more recent study carried out by Suzuki et al. demonstrated that the ocular surface was typically dominated by Propionibacterium in the young subjects and by Corynebacterium or Neisseriaceae in the elderly subjects (35).

Although metagenomic sequencing offers substantial information about the diversity of the ocular microbiome and reveal previously unidentified microbial species by the traditional culture-based methods, inconsistency remains between several studies using similar sequencing techniques (Table 1). Therefore, culture-based methods are sometimes combined with nonculture-based methods to prove the existence of a microbe. Most of the metagenomic sequencing results support Corynebacterium, Propionibacterium, and Staphylococcus as the dominant taxons of healthy ocular surface. This expands the list of the most common genera recovered by culture-based methods, i.e. the coagulase-negative Staphylococcus. Noteworthy, metagenomic sequencing results could also be complicated by several factors, such as small sample size (36), depth of swabs $(37,38)$, and contaminations from DNA extraction kit and PCR reagents $(39,40)$ and so forth. Nonetheless, it remains the best state-of-the-art tool for in situ profiling of a microbiota. Utilizing this powerful metagenomic sequencing tool, we have also characterized the intraocular microbiota of the aqueous humor from patients with ocular diseases that required surgical intervention. We found that each disease has a unique intraocular microbial signature, suggesting a potential link between intraocular microbiota and ocular health and diseases.

\section{FACTORS CHANGING THE OCULAR MICROBIOTA}

The ocular surface microbiota can be influenced by environmental conditions, age, gender, personal habits, contact lens wear, disease states, antibiotics, and infection etc (41). Understanding toward the factors that alter the intraocular microbiota is still in its infancy. As the intraocular space is relatively separated from the outer environment, it is reasonable to speculate that the intraocular microbiota is more imaginably associated with host factors.

Age and sex hormone have significant impacts on immune regulation and ocular health (33). Our study showed that age groups differs significantly in bacterial composition and metabolic functions, and that gender factor only affects $\beta$ but not $\alpha$ diversity of bacterial composition. Our data suggest that age and gender can collectively shape the ocular surface microbiome, while age appears to be a stronger factor in reshaping the ocular surface microbiome (33). However, some earlier studies showed contradictory findings: Ozkan et al (24). found no effect of age on the microbial a diversity and a higher Shannon diversity index in males; Zhou et al. found no effect of sex on the microbial diversity and a higher richness and Shannon diversity index in children less than 10 years old (30). This inconsistency may be explained by the fact that the techniques used were different in these studies. We used metagenomic sequencing approach which may detect a much broader range of microbes (33).

Dry eye syndrome is a multi-pathogenic factorial disease of the ocular surface characterized by loss of homeostasis of the tear film which results in excessive evaporation of tears in most of the

TABLE 1 | Core ocular surface microbiome in healthy adults.

Genera of bacteria

Number of Reference samples

Staphylococcus, Bacillus, Rhodococcus, Corynebacterium, Propionibacterium, Klebsiella, and Erwinia

Pseudomonas, Propionibacterium, Bradyrhizobium, Corynebacterium, Acinetobacter, Brevundimonas, Staphylococcus, Aquabacterium,

57

Sphingomonas, Streptococcus, Streptophyta, and Methylobacterium

Corynebacterium, Streptococcus, Propionibacterium, Bacillus, Staphylococcus, and Ralsontia

Corynebacterium, Pseudomonas, Staphylococcus, Acinetobacter, Streptococcus, Millisia, Anaerococcus, Finegoldia, Simonsiella, and

Veillonella

Corynebacteria, Propionibacteria, and Staphylococcus

Corynebacterium, Acinetobacteria, Pseudomonas, Sphingomonas, Streptococcus, Massilia, and Rothia

Propionibacterium, Staphylococcus, Escherichia, and Micrococcus

Pseudomonas, Acinetobacter, Bacillus, Chryseobacterium, and Corynebacterium

Propionibacterium, Corynebacterium, and Neisseriaceae
4 (2)

$\begin{array}{cc}57 & (2) \\ 4 & (29) \\ 105 & (30) \\ 31 & (31) \\ & \\ 107 & (32) \\ 45 & (24) \\ 90 & (33) \\ 54 & (34) \\ 36 & (35)\end{array}$


cases. Meibomian glands located in the eyelids are responsible for the secretion of oily components for the tear film to protect the ocular surface from overt dryness, discomfort, or damage. Meibomian gland dysfunction often leads to evaporative dry eye syndrome. Inconsistencies in the microbial species that changed by dry eye syndrome and meibomian gland dysfunction remain in several studies $(34,42,43)$. This may again be explained by sample size, sequencing approach, and different diagnostic criteria. For example, it has been reported that some cases of meibomian gland dysfunction overlap with not only dry eye syndrome but also blepharitis (44). No conclusive results have been achieved by these analyses, yet the results hinted that the ocular surface "resident microbiota", Corynebacterium, is likely associated with these diseases. However, it is still unclear that whether the change of the ocular surface microbiota is a cause or a consequence of the ocular surface disorders.

Patients with other diseases such as diabetes, high cholesterol and triglycerides, conjunctivitis, autoimmune diseases like Behcet's disease (BD), rheumatoid arthritis, and Sjögren's syndrome, which are linked with meibomian gland dysfunction and dry eye syndrome have also been reported with altered ocular surface microbiota (45-53). These suggest that endogenous host factors other than age and gender may be equally important in shaping the ocular surface microbiome, or the change of ocular surface microbiome may be secondary to meibomian gland dysfunction or dry eye syndrome. Further investigations are needed to dissociate data of patients with meibomian gland dysfunction or dry eye syndrome from those without in order to provide insights into finding the endogenous host factors that alter ocular surface microbiome.

\section{INTRAOCULAR INFLAMMATION}

Intraocular inflammation has two types: acute and chronic. The acute intraocular inflammation as observed in post-operative or post-traumatic endophthalmitis is normally caused by pathogenic microbes and is capable of inducing robust changes in blood-retina barrier permeability and subsequent infiltration of non-resident immune cells, such as polymorphonuclear leukocytes (PMNs) and macrophages (Figure 2) (54). The chronic form accounting for most intraocular inflammation appears to arise from a combination of predisposing genetic and environmental factors. A break of immune tolerance against endogenous antigens, followed by autoantibody production, dysregulation of effector and regulatory $\mathrm{T}$ cells, and infiltration of $\mathrm{T}$ lymphocytes and macrophages, is usually the mechanistic basis for chronic intraocular inflammation associated with inflammatory ocular diseases, particularly uveitis.

The eye is an immunologically privileged organ. The anterior chamber, the vitreous cavity, and the subretinal space of the eyes, are immune privileged sites where multiple mechanisms work together to inhibit overt immune responses (55). The conjunctiva and the interior of the eye are highly vascularized and home to many immune cells, suggesting that the eyes are under sophisticated regulation by immune system. Presumably due to an evolutionary adaption, our immune system uses several strategies to avoid intraocular inflammation, for example, immunological ignorance of eye-derived antigens, immune tolerance, and a local immunosuppressive or antiinflammatory microenvironment created by blood-retina barriers and immunosuppressive/anti-inflammatory molecules

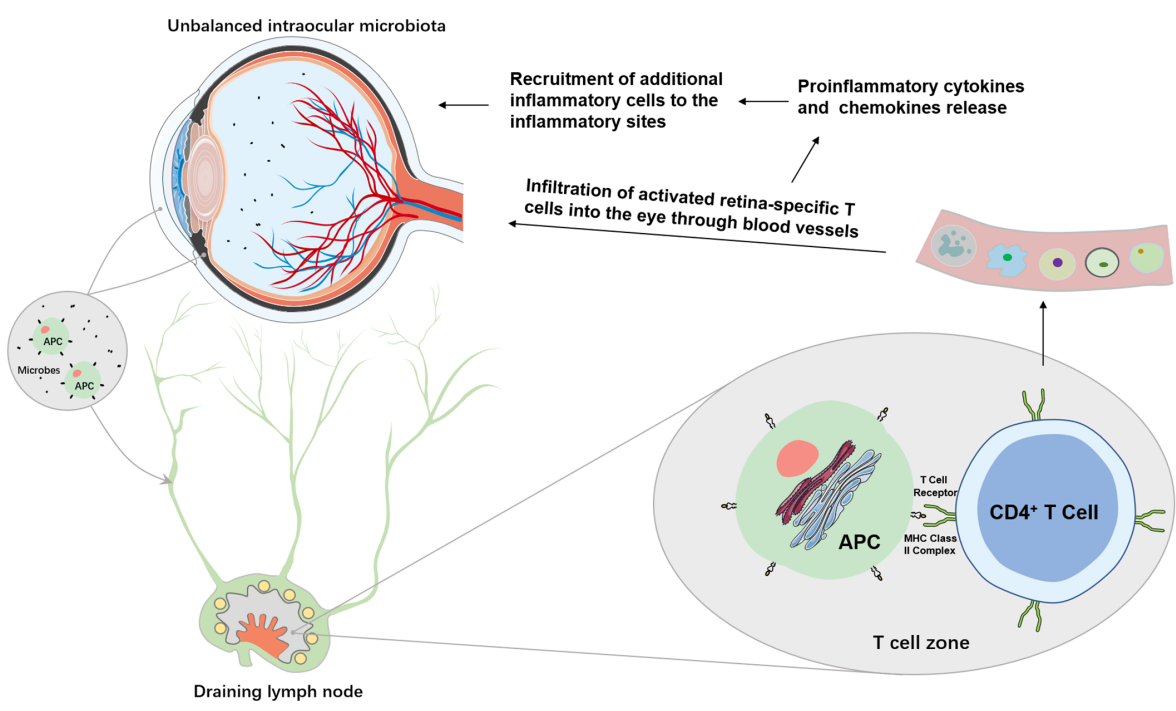

FIGURE 2 | Potential mechanisms of intraocular microbiome-mediated intraocular inflammation. Unbalanced intraocular microbiota can lead to overgrowth of pathogenic microbes which are surveyed by resident ocular APCs, such as ocular DCs. Immature APCs take up either the microbe as a whole or the microbial antigens in the eye to become mature. Through afferent lymphatic vessels, mature APCs migrate to the closest draining lymph nodes where they are recognized by $\mathrm{CD}^{+} \mathrm{T}$ cells. Activated retina-specific T cells migrate into the eyes to secret proinflammatory cytokines and chemokines which may disrupt the blood-retina barrier and recruit additional inflammatory cells and mediators to the eyes to cause intraocular inflammation. 
in ocular fluids or constitutively expressed by ocular parenchymal cells (55). These strategies are collectively known as ocular immune privilege. By virtue of ocular immune privilege, transplants into the eyes are not subjected to sightdestroying immune responses and inflammation. Antigen injected into these places induces peripheral tolerance to that antigen (56). A classic phenomenon is the anterior chamberassociated immune deviation (ACAID) in which injection of an antigen to the anterior chamber of the eye induces systemic immunoregulatory responses that are believed to protect the eye from future immune-mediated damage (57). Similarly, adenoassociated virus delivery to the subretinal space elicits only limited immune response $(58,59)$. However, in the face of antigen overload, the mechanisms of immune privilege cannot always effectively restrain the immune cells from infiltrating and responding. The C56BL/6 mice eyes intravitreally injected with 500 colony-forming unit (cfu) of Staphylococcus aureus were observed to reach $10^{7} \mathrm{cfu} 24$ hours post injection and eventually reduced the number to $5 \times 10^{3}$ cfu by 72 hours. During the 3 day course, mice had few infiltrating inflammatory cells and no microscopic retinal damage. By contrast, eyes intravitreally injected with $5,000 \mathrm{cfu}$ of the same microbes resulted in massive infiltration and severe damage to ocular structures (60).

\section{OCULAR INFLAMMATORY DISEASES ARE ASSOCIATED WITH NON-OCULAR MICROBIOTA}

The microbiota was once considered to be inert in immune homeostasis. However, over the past decades, pivotal roles of dysbiosis (changes in the gut commensal microbiota) in human health have been established. Dysbiosis has been implicated in various diseases associated with systemic inflammation, including rheumatoid arthritis, multiple sclerosis, inflammatory bowel disease, and type 1 diabetes (61-67). In recent years, gut commensals have also been involved in the pathogenesis of several non-infectious eye diseases like autoimmune uveitis, $\mathrm{AMD}$, and glaucoma.

The eye is protected by a prompt immune response to clear pathogens or antigens. However, inappropriate intraocular inflammation, such as those occurs in various forms of uveitis could be fatal to the eye and its visual function. Uveitis is a group of eye diseases characterized by acute or chronic intraocular inflammation of infectious or non-infectious origin. Autoimmune uveitis arises without known infectious stimuli. In humans, uveitis has been associated with human leukocyte antigen-B27 (HLA-B27), a prominent major histocompatibility complex (MHC) class I-allele expressed on the white blood cell surface, suggesting innate etiology (68). Patients with acute anterior uveitis have distinct intestinal microbial signature (69). Animal models have provided tremendous insights into its mechanistic basis. HLA-B27 transgenic rats exhibited altered cecal microbiota compared to healthy controls (70). Other mouse models of induced or spontaneous uveitis also showed ameliorated inflammation when commensals were removed or reduced. A classic mouse model of autoimmune uveitis is the experimental autoimmune uveitis (EAU) in which interphotoreceptor retinoid binding protein (IRBP) and heatkilled Mycobacterium tuberculosis are co-administered in complete Freund's adjuvant and ocular inflammation begins around day 10. Fecal microbiota transplantation with feces from BD patients significantly exacerbated EAU and increased the production of inflammatory cytokines (71). In EAU, an intestinal dysbiosis accompanies a disruption in intestinal homeostasis was demonstrated (72). Microbial ablation by raising mice in germ-free environment or microbial reduction by the treatment of a combination of broad-spectrum antibiotics in EAU reduce the severity of ocular inflammation (73). The direct connection between intestinal microbiota and the eye was confirmed in a spontaneous uveitis mouse model in $\mathrm{R} 161 \mathrm{H}$ mice which are engineered to express a transgene for $\mathrm{T}$ cell receptor (TCR) specific for IRBP. In these mice, retina-specific T cells are first activated by intestinal commensals in the gut through the autoreactive TCR and then trigger inflammation in the retina, implying that a commensal microbial antigen may mimic a retinal antigen to trigger autoimmune uveitis (Figure 2) (74). In line with this evidence, another study demonstrated that broad-spectrum oral antibiotics could attenuate EAU by increasing Tregs and decreasing effector $\mathrm{T}$ cells in the gut and extraintestinal tissues (75).

$\mathrm{AMD}$ is a progressive retinal degeneration and often associated with chronic low-grade intraocular inflammation. A substantial genome-wide association studies revealed that genetic variants in complement and various inflammatory pathway such as complement factor (CF) H,CFI, age-related maculopathy susceptibility 2 (ARMS2), tissue inhibitor of metalloproteinases3 (TIMP3), and matrix metallopeptidase 9 (MMP9), as well as in lipid pathway such as apolipoprotein $E(A P O E)$, lipase $C$ $(L I P C)$, cholesteryl ester transfer protein (CETP), and ATPbinding cassette transporter ( $A B C A 1)$ were associated with the disease $(76,77)$. The identified variants, however, explain only $46-71 \%$ of the genomic heritability of AMD (78). This may be attributed to additional variation not identified, or to genetic interaction with environmental factors such as smoking, diet or sunlight exposure (76). Commensal bacteria as one potential environmental influence could play a role in AMD development. There are several reasons for such presumption: (i) Microbes are involved in the regulation of host immunity and lipid metabolism both of which have profound effects on chronic low-grade inflammation and are important in the pathogenesis of AMD. (ii) Drusen in AMD eyes contain anti-infectious components such as complement components, apolipoprotein E, amyloid $\beta$, vitronectin, immunoglobulins and C1Q (79). (iii) As discussed earlier, gut microorganisms could send signals that exert distal effects on a remote organ like the eye. Indeed, several studies have linked commensal microbiota to AMD pathogenesis. Patients with AMD have shown distinct intestinal, oral, nasal, and pharyngeal microbial communities, highlighting potential role of mucosal surface microbes in the pathogenesis of AMD (80-82). Mice fed a high-glycemic diet 
developed hallmarks of AMD, such as retinal pigment epithelium (RPE) hypopigmentation and atrophy, lipofuscin accumulation, and photoreceptor degeneration, whereas mice fed the lower-glycemia diet did no $(83,84)$. High-fat diet feeding in mice significantly influenced gut microbiota composition and exacerbated laser-induced model of neovascular AMD, also known as choroidal neovascularization (85). In our preliminary study, we observed that several intraocular bacteria were associated specifically with AMD and significantly enriched in soft drusen from AMD patients implying that bacterial infection may be a previously unappreciated etiology of early AMD.

Gut and oral commensals have been implicated in glaucoma which involves local inflammatory response. Astafurov et al. demonstrated that patients with glaucoma had higher oral bacterial load than patients without glaucoma, and that lowdose subcutaneous lipopolysaccharide (LPS) in two separate animal models of glaucoma resulted in enhanced glaucomatous neural degeneration (86). DBA/2J mice, which spontaneously develop high intraocular pressure, mild intraocular inflammation and glaucoma by 6-8 months of age, have been frequently used as a murine model for glaucoma (87). Interestingly, $\mathrm{DBA} / 2 \mathrm{~J}$ mice raised in germ-free environment do not display typical axonal degeneration and neuronal loss at 12 months of age (88). The study demonstrated that $\mathrm{T}$ cells at least partially mediated the glaucomatous pathology in DBA/2J mice raised under specific-pathogen-free conditions (88). A more recent study found that compared to healthy subjects, the gut microbiota of patients with primary open-angle glaucoma had a different gut microbiota profile (89).

The molecular mechanisms underlying the altered gut microbiota and the progression of these ocular inflammatory diseases remain obscure. Further investigations are required to elucidate whether translocation of microbes and/or microbial products (e.g., LPS, peptidoglycan, short-chain fatty acids, and microbial DNA) from the gastrointestinal tract or other mucosal surfaces to the eye through blood circulation or ocular lymphatics occurs during the progression of diseases.

\section{MICROBIAL PATHOGENS AND HOST FACTORS IN INTRAOCULAR INFLAMMATION}

During an event of intraocular inflammation, the immunosuppressive environment of the eye is compromised when pathogens or antigens are detected by local immune surveillance. An immune response is usually initiated by innate receptors, such as Toll-like receptors (TLRs), located in the retina. TLRs generally recognize pathogenassociated molecular patterns (PAMPs) and damage-associated molecular patterns (DAMPs). The former comprise microbial structures/nucleic acid sequences, while the latter are usually molecules released from host cells following tissue injury or damage. The complex interactions between PAMPs/DAMPs and host immune system are mediated through multiple host factors including antigen presenting cells (APCs), MHCs, and inflammatory mediators (Figure 2).

\section{Toll-Like Receptors}

The activation of an innate immune response is followed by the recognition of PAMPs on the surface of microbes by a group of receptors called pattern recognition receptors (PRRs). Of the several different families of PRRs which includes TLRs, NODlike receptors, and mannose receptors, TLRs are the most important members and have been extensively researched in the field of intraocular inflammation. The TLRs are type 1 integral membrane receptors with an $\mathrm{N}$-terminal extracellular domain for ligand binding composed of leucine rich repeats and a C-terminal cytoplasmic Toll/IL-1 receptor (TIR) domain for intracellular signaling (90). Bacterial structural components such as LPS, peptidoglycan, lipids, and lipoproteins can be detected by TLRs on RPE cells, retinal microglia, astrocytes, and Müller cells. As of today, 10 functional TLRs have been identified in humans, while 12 TLRs have been identified in mice (91). TLR1, 2, 4, 5 and 6 are expressed on the cell surface and mainly recognize PAMPs derived from bacteria, fungi and protozoa. In contrast, TLR3, 7, 8 and 9 are expressed in the cytoplasmic compartment and primarily recognize nucleic acids derived from virus and bacteria (91). Upon ligand-receptor interactions, TLRs recruit adaptor molecules including Myeloid differentiating factor 88 (MyD88) and TIR domain containing adaptor inducing interferon $\beta$ (TRIF), TIR domain-containing adaptor protein (TIRAP) and TRIF-related adaptor molecule (TRAM). Stimulation of TLR signaling further induces nuclear factor kappa-B (NF-KB) nuclear translocation, or activation of interferon regulatory factors (IRFs), or mitogen-activate protein kinases (MAPKs) pathways to promote the expression of inflammatory mediators (92).

Previous studies have linked TLR signaling to inflammatory eye diseases (93-96). Significantly higher expression of TLR 2, 3, 4 , and 8 has been observed in $\mathrm{BD}$ patients as compared with healthy controls (93). A selective perturbation in the expression and function of TLR2 and 4 was observed on the neutrophils and monocytes of patients with acute anterior uveitis (AAU) (96), suggestive of microbial triggers and TLRs in the pathogenesis of AAU, as TLR2 or TLR4 stimulation by their ligands results in internalization of the cell surface receptors $(97,98)$. The activation of TLR4 by endotoxin induces a standard model of uveitis in rats, referred to as endotoxin-induced uveitis (99), although the molecular mechanisms by which endotoxin induces uveitis remain unknown. Injection of different TLR agonists into iris/ciliary body explants increased production of inflammatory cytokines TNF- $\alpha$, IL-6, IP-10/CXCL10, MCP-1. Intraocular injection of TLR agonist increased leukocyte interactions with the endothelium of the iris vasculature and chemotaxis into the iris tissue (100). Contradictorily, studies utilizing genetic mouse models demonstrated that TLR2, 3, 4, and 9 are highly redundant in the adjuvant effect needed to induce EAU and that diverse microbial infections may contribute to the pathogenesis of uveitis (101). TLRs may partially explain the experimental and clinical manifestations of immune-mediated uveitis implicating microbial triggers $(102,103)$. 


\section{Antigen-Presenting Cells}

Professional APCs include dendritic cells (DCs), macrophages and B cells. APCs express and use antigen-specific surface receptors, such as PRRs, to recognize and bind their targets, such as PAMPs or DAMPs. Binding of surface PRRs to microbial PAMPs or whole bacteria induces phagocytosis of microbial pathogens by DCs or macrophages. A previous study demonstrated that the protein expression of functional endotoxin receptor TLR4 and its associated LPS receptor complex (CD14 and MD-2) was restricted to resident APCs in the normal human uvea, consisting mainly of HLA-DR ${ }^{+}$DCs. These APCs appeared to be strategically located in perivascular and subepithelial sites to detect and respond to blood-borne or intraocular LPS of Gram-negative bacteria (104). These observations were confirmed by another study showing the expression of the functional TLR4 and CD14 in human ciliary body and TLR4 in human iris endothelial cells (105), supporting the notion that microbial triggers, in particular LPS of Gramnegative bacteria may trigger AAU by activating TLR4expressing resident uveal APCs. RPE cells in vitro display many characteristics typical of APC yet are poor inducers of lymphocyte proliferation (106). RPE cells express proteins for TLR1-6 and 9, and are capable of secreting IL-8 after stimulation by PAMPs (107). APCs themselves may release cytokines to directly influence the development of uveitis (108) or may pathogenically link to uveitis through regulating the function of T cells $(109,110)$.

\section{Major Histocompatibility Complexes}

After binding to respective PRR ligands, APCs internalize and degrade their targets by initiating phagocytosis or clathrinmediated endocytosis, and then display the epitope by MHCs for recognition by immunologic structures like TCRs on appropriate $\mathrm{T}$ cells. MHCs are cell surface proteins essential for adaptive immune response. Two types of MHCs display antigens: class I MHCs and class II MHCs. Class I MHC receptors are produced by all nucleated cells and display endogenous antigens to activate $\mathrm{CD}^{+}$cytotoxic $\mathrm{T}$ cells. Class II MHC receptors normally express only on professional APCs (111). HLA-B27 is present in about $50 \%$ of all patients with AAU and is the strongest genetic factor for AAU. Both HLA-B27 transgenic Lewis rats and HLA-B27 transgenic Fischer rats developed gut inflammation (112). The rats develop diarrhea, peripheral arthritis, and spondylitis, while removal of microbiota significantly reduces the symptoms, however, these rats do not develop uveitis $(68,113)$. Similarly, in humans, the majority of individuals who are HLA-B27-positive do not develop AAU or other autoimmune diseases, implying the involvement of other genes or environmental factors in the development of uveitis. Some literature suggests the involvement of microbial triggers in disease development, in particular Gram-negative bacteria $(114,115)$.

\section{Inflammatory Mediators}

Proinflammatory mediators released by retinal microglia, endothelial, or Müller cells are critical for recruiting PMNs and macrophages to sites of inflammation or infection. In addition to pathogen clearance, PMNs and macrophages produce cytokines and chemokines to increase blood-retinal barrier permeability, facilitate migration of cells, and recruit additional inflammatory cells and mediators to the inflammatory sites. Many of the proinflammatory mediators increased in experimental animal models of intraocular inflammation are also diagnosed with increased levels in the aqueous and vitreous humor of humans with inflammatory eye diseases (116). Several inflammatory mediators play essential roles in mounting an inflammatory response. $\mathrm{TNF} \alpha$ is a pleiotropic cytokine that rapidly upregulates following tissue injury and can be produced by activated macrophages, T cells, and natural killer cells (117). In the eye, TNF $\alpha$ appears to mediate the pathogenesis of intraocular inflammation, neovascular and retinal degeneration by stimulating other retinal cells to produce cytokines, such as interferon $\gamma$, IL-1 $\beta$, IL-2, IL-4, IL-6, IL-8, and IL-10, and other proinflammatory molecules, such as vascular cell adhesion molecule-1 (VCAM-1), intercellular cell adhesion molecule-1 (ICAM-1), and macrophage inflammatory protein (MIP)-1 $\alpha$, MIP-2, monocyte chemotactic protein-1 (MCP-1), and CXCL1 (117-120). During an intraocular inflammation, elevated levels of TNF $\alpha$ correlated with worsen visual acuity (120). TNF $\alpha^{-/-}$ mice were subjected to greater bacterial growth, intraocular inflammation, and ocular structural damage after an infection (121). While bacterial growth was similar between wild-type controls and $\mathrm{IL}_{-} 6^{-/-}$and $\mathrm{CXCL}^{-/-}$mice, the intraocular inflammation was attenuated in mice lacking CXCL-1, but not IL-6 (122).

\section{TARGETING OCULAR MICROBIOTA AS NOVEL THERAPIES FOR INTRAOCULAR INFLAMMATION}

Current treatment for intraocular inflammation includes steroids, anti-cytokine biologics, and non-biologic immunosuppressive agents therapies. While corticosteroids remain the most potent and efficacious drug for treating intraocular inflammation, results from the corticosteroids use are not optimal and poor control in some cases (123). Patients diagnosed with uveitis require prolonged repeated intravitreal injections which usually leads to many side effects, such as hyperglycemia and dysregulated bone metabolic homeostasis (124). The drugs most commonly used in replacement of corticosteroids are non-biologic immunosuppressive agents including azathioprine, methotrexate, mycophenolate and cyclosporine, all of which have been reported with potentials for significant side effects (123). The more recent anti-cytokine biologics have greatly changed the therapeutic options for noninfectious uveitis. In 2016, adalimumab as the first anti-TNF $\alpha$ biologic, was approved by the FDA in the treatment of noninfectious intermedia uveitis, posterior uveitis, and panuveitis. Similar anti-TNFo biologics, such as infliximab and golimumab, could also exert significant anti-inflammatory effects. In $\mathrm{TNF}^{-/-}$ mice, the intraocular inflammation and cytokine production was dramatically reduced in the experimental model of endophthalmitis. Unfortunately, $\mathrm{TNF}^{-/-}$mice displayed poor retinal function 
retention, presumably due to increased bacterial load (121), providing rationale for the development of novel and more targeted therapies.

$\mathrm{R} 161 \mathrm{H}$ mice which spontaneously developed uveitis or EAU mouse models are devoid of disease phenotypes when raised in germ-free environment or treated with broad-spectrum antibiotics $(73,74)$. Mechanistic basis to these phenomena has been proven by Horai et al. to be originated from gut microbeactivated T cells (74). Our recent findings of the existence of intraocular microbes imply that intraocular commensals might also contribute to the pathogenesis of uveitis, as germ-free environment and antibiotics theoretically also remove intraocular commensals, although direct evidence for this notion is still lacking. Therapies manipulating commensal microbiome have been emerged as a novel strategy to prime the host immune system to counteract several inflammatory diseases, such as inflammatory bowel disease, graft-vs.-host disease, HIV infection, and psychological-stress-induced inflammation (125-127). This is presumably due to the reason that host microbiota could shape the host immune system to dictate the proinflammatory effects of other proinflammatory stimuli (128). A recent study demonstrated that the combination of remodeling of gut microbiome and microglia inhibition significantly attenuate the progression of EAU after inflammation onset (129). A potential explanation is that antigens from commensals reprogram naïve $\mathrm{CD}^{+} \mathrm{T}$ cells to the regulatory $\mathrm{T}$ cells lineage to restrain lymphocyte response (130). Nonetheless, it remains to be determined whether the clinical intervention targeting gut microbiome is efficacious in improving uveitis humans.

\section{CONCLUSION}

Commensals are a large source of intrinsic antigens that are continuously sensed by the immune system but typically do not elicit inflammation. Since the discovery of ocular surface microbiota, their interactions with the innate immunity of the ocular surface have been explored by many researchers. Up to

\section{REFERENCES}

1. McDermott AM. Antimicrobial compounds in tears. Exp Eye Res (2013) 117:53-61. doi: 10.1016/j.exer.2013.07.014

2. Graham JE, Moore JE, Jiru X, Moore JE, Goodall EA, Dooley JS, et al. Ocular pathogen or commensal: a PCR-based study of surface bacterial flora in normal and dry eyes. Invest Ophthalmol Vis Sci (2007) 48(12):5616-23. doi: 10.1167/iovs.07-0588

3. Willcox MD. Characterization of the normal microbiota of the ocular surface. Exp Eye Res (2013) 117:99-105. doi: 10.1016/j.exer.2013.06.003

4. Miller D, Iovieno A. The role of microbial flora on the ocular surface. Curr Opin Allergy Clin Immunol (2009) 9(5):466-70. doi: 10.1097/ACI.0b013e3283303e1b

5. Ueta M. Innate immunity of the ocular surface and ocular surface inflammatory disorders. Cornea (2008) 27(Suppl 1):S31-40. doi: 10.1097/ ICO.0b013e31817f2a7f

6. Owens CD, Stoessel K. Surgical site infections: epidemiology, microbiology and prevention. J Hosp Infect (2008) 70(Suppl 2):3-10. doi: 10.1016/S01956701(08)60017-1 date, the intraocular microbiota could be considered a black box. The interior of the eye is highly vascularized and contains miscellaneous types of immune cells or immune mediators. How the intraocular microbiota and intraocular immune environment interplay to modulate inflammatory eye diseases, such as uveitis, remains an open question. Most of the microorganisms that constitute the intraocular microbiome are sparse in number, anaerobic, and extremely difficult to culture. Our laboratory has employed state-of-the-art metagenomic sequencing, combined with cultural technique and micrographical analysis to unveil the mask of intraocular microbiota, which may advance our understanding toward the mechanisms of intraocular inflammation. However, puzzles as to how commensals occupy the inside of the eye, whether the intestinal microbiota contribute to or modulate the intraocular commensals, and how intraocular commensals regulate the innate and adaptive ocular immune responses await to be answered. This process is most likely involved roles of TLRs, APCs, MHCs, and many inflammatory mediators. Further delineation of the commensal types that altered in ocular inflammatory diseases, and clarification of the question that whether the commensals as a whole or specific commensal epitopes are mainly responsible for disease progression are of significant importance to expand our knowledge of the ocular immune system and intraocular inflammation.

\section{DATA AVAILABILITY STATEMENT}

The original contributions presented in the study are included in the article/supplementary material; further inquiries can be directed to the corresponding authors.

\section{AUTHOR CONTRIBUTIONS}

JL and LW wrote the manuscript. SY prepared the figures. All authors contributed to the article and approved the submitted version.

7. Cristina ML, Sartini M, Schinca E, Ottria G, Spagnolo AM. Operating room environment and surgical site infections in arthroplasty procedures. J Prev Med Hyg (2016) 57(3):E142-E8.

8. Rahmani S, Eliott D. Postoperative Endophthalmitis: A Review of Risk Factors, Prophylaxis, Incidence, Microbiology, Treatment, and Outcomes. Semin Ophthalmol (2018) 33(1):95-101. doi: 10.1080/08820538.2017. 1353826

9. Damgaard C, Magnussen K, Enevold C, Nilsson M, Tolker-Nielsen T, Holmstrup $\mathrm{P}$, et al. Viable bacteria associated with red blood cells and plasma in freshly drawn blood donations. PloS One (2015) 10(3):e0120826. doi: 10.1371/journal.pone.0120826

10. Potgieter M, Bester J, Kell DB, Pretorius E. The dormant blood microbiome in chronic, inflammatory diseases. FEMS Microbiol Rev (2015) 39(4):567-91. doi: 10.1093/femsre/fuv013

11. Paisse S, Valle C, Servant F, Courtney M, Burcelin R, Amar J, et al. Comprehensive description of blood microbiome from healthy donors assessed by 16S targeted metagenomic sequencing. Transfusion (2016) 56 (5):1138-47. doi: 10.1111/trf.13477 
12. Schierwagen R, Alvarez-Silva C, Madsen MSA, Kolbe CC, Meyer C, Thomas D, et al. Circulating microbiome in blood of different circulatory compartments. Gut (2019) 68(3):578-80. doi: 10.1136/gutjnl-2018-316227

13. Sorrentino FS, Matteini S, Bonifazzi C, Sebastiani A, Parmeggiani F. Diabetic retinopathy and endothelin system: microangiopathy versus endothelial dysfunction. Eye (Lond) (2018) 32(7):1157-63. doi: 10.1038/s41433-0180032-4

14. Beli E, Yan Y, Moldovan L, Vieira CP, Gao R, Duan Y, et al. Restructuring of the Gut Microbiome by Intermittent Fasting Prevents Retinopathy and Prolongs Survival in db/db Mice. Diabetes (2018) 67(9):1867-79. doi: $10.2337 / \mathrm{db} 18-0158$

15. Sinclair SH, Schwartz SS. Diabetic Retinopathy-An Underdiagnosed and Undertreated Inflammatory, Neuro-Vascular Complication of Diabetes. Front Endocrinol (Lausanne) (2019) 10:843. doi: 10.3389/fendo.2019.00843

16. Camelo S, Castellanos J, Lafage M, Lafon M. Rabies virus ocular disease: Tcell-dependent protection is under the control of signaling by the $\mathrm{p} 55$ tumor necrosis factor alpha receptor, p55TNFR. J Virol (2001) 75(7):3427-34. doi: 10.1128/JVI.75.7.3427-3434.2001

17. Egger SF, Buxbaum A, Georgopoulos M, Scholda C, Vecsei VP, HuberSpitzy V, et al. Bacterial growth in human vitreous humor. Exp Eye Res (1997) 65(6):791-5. doi: 10.1006/exer.1997.0385

18. Metchnikoff E. On aqueous humour, micro-organisms and immunity. J Pathol Bacteriol (1892) 1:13-20.

19. Goto H, Usui Y, Umazume A, Uchida K, Eishi Y. Propionibacterium acnes as a possible pathogen of granuloma in patients with ocular sarcoidosis. $\mathrm{Br} \mathrm{J}$ Ophthalmol (2017) 101(11):1510-3. doi: 10.1136/bjophthalmol-2016-309248

20. Nagata K, Eishi $Y$, Uchida K, Yoneda K, Hatanaka H, Yasuhara T, et al. Immunohistochemical Detection of Propionibacterium acnes in the Retinal Granulomas in Patients with Ocular Sarcoidosis. Sci Rep (2017) 7(1):15226. doi: 10.1038/s41598-017-15710-0

21. Hori Y, Maeda N, Sakamoto M, Koh S, Inoue T, Tano Y. Bacteriologic profile of the conjunctiva in the patients with dry eye. Am J Ophthalmol (2008) 146(5):729-34. doi: 10.1016/j.ajo.2008.06.003

22. Fernandez-Rubio ME, Rebolledo-Lara L, Martinez-Garcia M, AlarconTomas M, Cortes-Valdes C. The conjunctival bacterial pattern of diabetics undergoing cataract surgery. Eye (Lond) (2010) 24(5):825-34. doi: 10.1038/ eye.2009.218

23. Schabereiter-Gurtner C, Maca S, Rolleke S, Nigl K, Lukas J, Hirschl A, et al. 16S rDNA-based identification of bacteria from conjunctival swabs by PCR and DGGE fingerprinting. Invest Ophthalmol Vis Sci (2001) 42(6):1164-71.

24. Ozkan J, Nielsen S, Diez-Vives C, Coroneo M, Thomas T, Willcox M. Temporal Stability and Composition of the Ocular Surface Microbiome. Sci Rep (2017) 7(1):9880. doi: 10.1038/s41598-017-10494-9

25. Schloss PD, Handelsman J. Status of the microbial census. Microbiol Mol Biol Rev (2004) 68(4):686-91. doi: 10.1128/MMBR.68.4.686-691.2004

26. Moeller CT, Branco BC, Yu MC, Farah ME, Santos MA, Hofling-Lima AL. Evaluation of normal ocular bacterial flora with two different culture media. Can J Ophthalmol (2005) 40(4):448-53. doi: 10.1139/i05-014

27. Clarridge JE3. Impact of $16 \mathrm{~S}$ rRNA gene sequence analysis for identification of bacteria on clinical microbiology and infectious diseases. Clin Microbiol Rev (2004) 17(4):840-62. doi: 10.1128/CMR.17.4.840-862.2004

28. Rausch P, Ruhlemann M, Hermes BM, Doms S, Dagan T, Dierking K, et al. Comparative analysis of amplicon and metagenomic sequencing methods reveals key features in the evolution of animal metaorganisms. Microbiome (2019) 7(1):133. doi: 10.1186/s40168-019-0743-1

29. Dong Q, Brulc JM, Iovieno A, Bates B, Garoutte A, Miller D, et al. Diversity of bacteria at healthy human conjunctiva. Invest Ophthalmol Vis Sci (2011) 52(8):5408-13. doi: 10.1167/iovs.10-6939

30. Zhou Y, Holland MJ, Makalo P, Joof H, Roberts CH, Mabey DC, et al. The conjunctival microbiome in health and trachomatous disease: a case control study. Genome Med (2014) 6(11):99. doi: 10.1186/s13073-014-0099-x

31. Huang Y, Yang B, Li W. Defining the normal core microbiome of conjunctival microbial communities. Clin Microbiol Infect (2016) 22 (7):643 e7- e12. doi: 10.1016/j.cmi.2016.04.008

32. Doan T, Akileswaran L, Andersen D, Johnson B, Ko N, Shrestha A, et al. Paucibacterial Microbiome and Resident DNA Virome of the Healthy Conjunctiva. Invest Ophthalmol Vis Sci (2016) 57(13):5116-26. doi: $10.1167 /$ iovs.16-19803
33. Wen X, Miao L, Deng Y, Bible PW, Hu X, Zou Y, et al. The Influence of Age and Sex on Ocular Surface Microbiota in Healthy Adults. Invest Ophthalmol Vis Sci (2017) 58(14):6030-7. doi: 10.1167/iovs.17-22957

34. Li Z, Gong Y, Chen S, Li S, Zhang Y, Zhong H, et al. Comparative portrayal of ocular surface microbe with and without dry eye. J Microbiol (2019) 57 (11):1025-32. doi: 10.1007/s12275-019-9127-2

35. Suzuki T, Sutani T, Nakai H, Shirahige K, Kinoshita S. The Microbiome of the Meibum and Ocular Surface in Healthy Subjects. Invest Ophthalmol Vis Sci (2020) 61(2):18. doi: 10.1167/iovs.61.2.18

36. Kelly BJ, Gross R, Bittinger K, Sherrill-Mix S, Lewis JD, Collman RG, et al. Power and sample-size estimation for microbiome studies using pairwise distances and PERMANOVA. Bioinformatics (2015) 31(15):2461-8. doi: 10.1093/bioinformatics/btv183

37. Tedeschi S, Negosanti L, Sgarzani R, Trapani F, Pignanelli S, Battilana M, et al. Superficial swab versus deep-tissue biopsy for the microbiological diagnosis of local infection in advanced-stage pressure ulcers of spinal-cordinjured patients: a prospective study. Clin Microbiol Infect (2017) 23 (12):943-7. doi: 10.1016/j.cmi.2017.04.015

38. Prast-Nielsen S, Tobin AM, Adamzik K, Powles A, Hugerth LW, Sweeney C, et al. Investigation of the skin microbiome: swabs vs. biopsies. $\mathrm{Br} J$ Dermatol (2019) 181(3):572-9. doi: 10.1111/bjd.17691

39. Glassing A, Dowd SE, Galandiuk S, Davis B, Chiodini RJ. Inherent bacterial DNA contamination of extraction and sequencing reagents may affect interpretation of microbiota in low bacterial biomass samples. Gut Pathog (2016) 8:24. doi: 10.1186/s13099-016-0103-7

40. Knight R, Vrbanac A, Taylor BC, Aksenov A, Callewaert C, Debelius J, et al. Best practices for analysing microbiomes. Nat Rev Microbiol (2018) 16 (7):410-22. doi: 10.1038/s41579-018-0029-9

41. Lu LJ, Liu J. Human Microbiota and Ophthalmic Disease. Yale J Biol Med (2016) 89(3):325-30.

42. Zhang Y, Liu ZR, Chen H, Fan YC, Duo J, Zheng H, et al. Comparison on conjunctival sac bacterial flora of the seniors with dry eye in Ganzi autonomous prefecture. Int J Ophthalmol (2013) 6(4):452-7. doi: 10.3980/ j.issn.2222-3959.2013.04.08

43. Dong X, Wang Y, Wang W, Lin P, Huang Y. Composition and Diversity of Bacterial Community on the Ocular Surface of Patients With Meibomian Gland Dysfunction. Invest Ophthalmol Vis Sci (2019) 60(14):4774-83. doi: $10.1167 /$ iovs.19-27719

44. Soh Qin R, Tong Hak Tien L. Healthcare delivery in meibomian gland dysfunction and blepharitis. Ocul Surf (2019) 17(2):176-8. doi: 10.1016/ j.jtos.2018.11.007

45. Markoulli M, Flanagan J, Tummanapalli SS, Wu J, Willcox M. The impact of diabetes on corneal nerve morphology and ocular surface integrity. Ocul Surf (2018) 16(1):45-57. doi: 10.1016/j.jtos.2017.10.006

46. Li S, Yi G, Peng H, Li Z, Chen S, Zhong H, et al. How Ocular Surface Microbiota Debuts in Type 2 Diabetes Mellitus. Front Cell Infect Microbiol (2019) 9:202. doi: 10.3389/fcimb.2019.00202

47. Shivaji S. We are not alone: a case for the human microbiome in extra intestinal diseases. Gut Pathog (2017) 9:13. doi: 10.1186/s13099-017-0163-3

48. Thomason CA, Leon A, Kirkpatrick LT, Belden LK, Hawley DM. Eye of the Finch: characterization of the ocular microbiome of house finches in relation to mycoplasmal conjunctivitis. Environ Microbiol (2017) 19(4):1439-49. doi: 10.1111/1462-2920.13625

49. Consolandi C, Turroni S, Emmi G, Severgnini M, Fiori J, Peano C, et al. Behcet's syndrome patients exhibit specific microbiome signature. Autoimmun Rev (2015) 14(4):269-76. doi: 10.1016/j.autrev.2014.11.009

50. Terzulli M, Contreras-Ruiz L, Kugadas A, Masli S, Gadjeva M. TSP-1 Deficiency Alters Ocular Microbiota: Implications for Sjogren's Syndrome Pathogenesis. J Ocul Pharmacol Ther (2015) 31(7):413-8. doi: 10.1089/jop.2015.0017

51. de Paiva CS, Jones DB, Stern ME, Bian F, Moore QL, Corbiere S, et al. Altered Mucosal Microbiome Diversity and Disease Severity in Sjogren Syndrome. Sci Rep (2016) 6:23561. doi: 10.1038/srep23561

52. Tsigalou C, Stavropoulou E, Bezirtzoglou E. Current Insights in Microbiome Shifts in Sjogren's Syndrome and Possible Therapeutic Interventions. Front Immunol (2018) 9:1106. doi: 10.3389/fimmu.2018.01106

53. Zaheer M, Wang C, Bian F, Yu Z, Hernandez H, de Souza RG, et al. Protective role of commensal bacteria in Sjogren Syndrome. J Autoimmun (2018) 93:45-56. doi: 10.1016/j.jaut.2018.06.004 
54. Callegan MC, Gilmore MS, Gregory M, Ramadan RT, Wiskur BJ, Moyer AL, et al. Bacterial endophthalmitis: therapeutic challenges and host-pathogen interactions. Prog Retin Eye Res (2007) 26(2):189-203. doi: 10.1016/ j.preteyeres.2006.12.001

55. Streilein JW. Ocular immune privilege: therapeutic opportunities from an experiment of nature. Nat Rev Immunol (2003) 3(11):879-89. doi: 10.1038/ nri1224

56. Stein-Streilein J. Immune regulation and the eye. Trends Immunol (2008) 29 (11):548-54. doi: 10.1016/j.it.2008.08.002

57. Cone RE, Pais R. Anterior Chamber-Associated Immune Deviation (ACAID): An Acute Response to Ocular Insult Protects from Future Immune-Mediated Damage? Ophthalmol Eye Dis (2009) 1:33-40. doi: $10.4137 /$ oed.s2858

58. Yiu G, Chung SH, Mollhoff IN, Nguyen UT, Thomasy SM, Yoo J, et al. Suprachoroidal and Subretinal Injections of AAV Using Transscleral Microneedles for Retinal Gene Delivery in Nonhuman Primates. Mol Ther Methods Clin Dev (2020) 16:179-91. doi: 10.1016/j.omtm.2020.01.002

59. Anand V, Chirmule N, Fersh M, Maguire AM, Bennett J. Additional transduction events after subretinal readministration of recombinant adeno-associated virus. Hum Gene Ther (2000) 11(3):449-57. doi: 10.1089/10430340050015914

60. Engelbert M, Gilmore MS. Fas ligand but not complement is critical for control of experimental Staphylococcus aureus Endophthalmitis. Invest Ophthalmol Vis Sci (2005) 46(7):2479-86. doi: 10.1167/iovs.04-1139

61. Maeda Y, Takeda K. Role of Gut Microbiota in Rheumatoid Arthritis. J Clin Med (2017) 6(6):60. doi: 10.3390/jcm6060060

62. Maeda Y, Takeda K. Host-microbiota interactions in rheumatoid arthritis. Exp Mol Med (2019) 51(12):1-6. doi: 10.1038/s12276-019-0283-6

63. Cekanaviciute E, Yoo BB, Runia TF, Debelius JW, Singh S, Nelson CA, et al. Gut bacteria from multiple sclerosis patients modulate human T cells and exacerbate symptoms in mouse models. Proc Natl Acad Sci U S A (2017) 114 (40):10713-8. doi: 10.1073/pnas.1711235114

64. Gulden E, Wong FS, Wen L. The gut microbiota and Type 1 Diabetes. Clin Immunol (2015) 159(2):143-53. doi: 10.1016/j.clim.2015.05.013

65. Zheng P, Li Z, Zhou Z. Gut microbiome in type 1 diabetes: A comprehensive review. Diabetes Metab Res Rev (2018) 34(7):e3043. doi: 10.1002/dmrr.3043

66. Matsuoka K, Kanai T. The gut microbiota and inflammatory bowel disease. Semin Immunopathol (2015) 37(1):47-55. doi: 10.1007/s00281-014-0454-4

67. Kostic AD, Xavier RJ, Gevers D. The microbiome in inflammatory bowel disease: current status and the future ahead. Gastroenterology (2014) 146 (6):1489-99. doi: 10.1053/j.gastro.2014.02.009

68. Rosenbaum JT, Asquith M. The microbiome and HLA-B27-associated acute anterior uveitis. Nat Rev Rheumatol (2018) 14(12):704-13. doi: 10.1038/ s41584-018-0097-2

69. Huang X, Ye Z, Cao Q, Su G, Wang Q, Deng J, et al. Gut Microbiota Composition and Fecal Metabolic Phenotype in Patients With Acute Anterior Uveitis. Invest Ophthalmol Vis Sci (2018) 59(3):1523-31. doi: 10.1167/iovs.17-22677

70. Lin P, Bach M, Asquith M, Lee AY, Akileswaran L, Stauffer P, et al. HLA-B27 and human beta2-microglobulin affect the gut microbiota of transgenic rats. PloS One (2014) 9(8):e105684. doi: 10.1371/journal.pone.0105684

71. Ye Z, Zhang N, Wu C, Zhang X, Wang Q, Huang X, et al. A metagenomic study of the gut microbiome in Behcet's disease. Microbiome (2018) 6 (1):135. doi: 10.1186/s40168-018-0520-6

72. Janowitz C, Nakamura YK, Metea C, Gligor A, Yu W, Karstens L, et al. Disruption of Intestinal Homeostasis and Intestinal Microbiota During Experimental Autoimmune Uveitis. Invest Ophthalmol Vis Sci (2019) 60 (1):420-9. doi: 10.1167/iovs.18-24813

73. Heissigerova J, Seidler Stangova P, Klimova A, Svozilkova P, Hrncir T, Stepankova R, et al. The Microbiota Determines Susceptibility to Experimental Autoimmune Uveoretinitis. J Immunol Res (2016) 2016:5065703. doi: 10.1155/2016/5065703

74. Horai R, Zarate-Blades CR, Dillenburg-Pilla P, Chen J, Kielczewski JL, Silver $\mathrm{PB}$, et al. Microbiota-Dependent Activation of an Autoreactive T Cell Receptor Provokes Autoimmunity in an Immunologically Privileged Site. Immunity (2015) 43(2):343-53. doi: 10.1016/j.immuni.2015.07.014

75. Nakamura YK, Metea C, Karstens L, Asquith M, Gruner H, Moscibrocki C, et al. Gut Microbial Alterations Associated With Protection From
Autoimmune Uveitis. Invest Ophthalmol Vis Sci (2016) 57(8):3747-58. doi: $10.1167 /$ iovs.16-19733

76. Fritsche LG, Igl W, Bailey JN, Grassmann F, Sengupta S, Bragg-Gresham JL, et al. A large genome-wide association study of age-related macular degeneration highlights contributions of rare and common variants. Nat Genet (2016) 48(2):134-43. doi: 10.1038/ng.3448

77. Fritsche LG, Chen W, Schu M, Yaspan BL, Yu Y, Thorleifsson G, et al. Seven new loci associated with age-related macular degeneration. Nat Genet (2013) 45(4):433-99e1-2. doi: 10.1038/ng.2578

78. Warwick A, Lotery A. Genetics and genetic testing for age-related macular degeneration. Eye (Lond) (2018) 32(5):849-57. doi: 10.1038/eye.2017.245

79. Wen X, Hu X, Miao L, Ge X, Deng Y, Bible PW, et al. Epigenetics, microbiota, and intraocular inflammation: New paradigms of immune regulation in the eye. Prog Retin Eye Res (2018) 64:84-95. doi: 10.1016/j.preteyeres.2018.01.001

80. Zinkernagel MS, Zysset-Burri DC, Keller I, Berger LE, Leichtle AB, Largiader $\mathrm{CR}$, et al. Association of the Intestinal Microbiome with the Development of Neovascular Age-Related Macular Degeneration. Sci Rep (2017) 7:40826. doi: 10.1038/srep40826

81. Rullo J, Far PM, Quinn M, Sharma N, Bae S, Irrcher I, et al. Local oral and nasal microbiome diversity in age-related macular degeneration. Sci Rep (2020) 10(1):3862. doi: 10.1038/s41598-020-60674-3

82. Ho EXP, Cheung CMG, Sim S, Chu CW, Wilm A, Lin CB, et al. Human pharyngeal microbiota in age-related macular degeneration. PloS One (2018) 13(8):e0201768. doi: 10.1371/journal.pone.0201768

83. Rowan S, Jiang S, Korem T, Szymanski J, Chang ML, Szelog J, et al. Involvement of a gut-retina axis in protection against dietary glycemiainduced age-related macular degeneration. Proc Natl Acad Sci U S A (2017) 114(22):E4472-81. doi: 10.1073/pnas.1702302114

84. Uchiki T, Weikel KA, Jiao W, Shang F, Caceres A, Pawlak D, et al. Glycationaltered proteolysis as a pathobiologic mechanism that links dietary glycemic index, aging, and age-related disease (in nondiabetics). Aging Cell (2012) 11 (1):1-13. doi: 10.1111/j.1474-9726.2011.00752.x

85. Andriessen EM, Wilson AM, Mawambo G, Dejda A, Miloudi K, Sennlaub F, et al. Gut microbiota influences pathological angiogenesis in obesity-driven choroidal neovascularization. EMBO Mol Med (2016) 8(12):1366-79. doi: 10.15252/emmm.201606531

86. Astafurov K, Elhawy E, Ren L, Dong CQ, Igboin C, Hyman L, et al. Oral microbiome link to neurodegeneration in glaucoma. PloS One (2014) 9(9): e104416. doi: 10.1371/journal.pone.0104416

87. Libby RT, Anderson MG, Pang IH, Robinson ZH, Savinova OV, Cosma IM, et al. Inherited glaucoma in DBA/2J mice: pertinent disease features for studying the neurodegeneration. Vis Neurosci (2005) 22(5):637-48. doi: $10.1017 /$ S0952523805225130

88. Chen H, Cho KS, Vu THK, Shen CH, Kaur M, Chen G, et al. Commensal microflora-induced $\mathrm{T}$ cell responses mediate progressive neurodegeneration in glaucoma. Nat Commun (2018) 9(1):3209. doi: 10.1038/s41467-018-05681-9

89. Gong H, Zhang S, Li Q, Zuo C, Gao X, Zheng B, et al. Gut microbiota compositional profile and serum metabolic phenotype in patients with primary open-angle glaucoma. Exp Eye Res (2020) 191:107921. doi: 10.1016/j.exer.2020.107921

90. Botos I, Segal DM, Davies DR. The structural biology of Toll-like receptors. Structure (2011) 19(4):447-59. doi: 10.1016/j.str.2011.02.004

91. Chang JH, McCluskey PJ, Wakefield D. Recent advances in Toll-like receptors and anterior uveitis. Clin Exp Ophthalmol (2012) 40(8):821-8. doi: $10.1111 /$ j.1442-9071.2012.02797.x

92. Kawai T, Akira S. Toll-like receptors and their crosstalk with other innate receptors in infection and immunity. Immunity (2011) 34(5):637-50. doi: 10.1016/j.immuni.2011.05.006

93. Liu X, Wang C, Ye Z, Kijlstra A, Yang P. Higher expression of Toll-like receptors 2, 3, 4, and 8 in ocular Behcet's disease. Invest Ophthalmol Vis Sci (2013) 54(9):6012-7. doi: 10.1167/iovs.13-12159

94. Fang J, Chen L, Tang J, Hou S, Liao D, Ye Z, et al. Association Between Copy Number Variations of TLR7 and Ocular Behcet's Disease in a Chinese Han Population. Invest Ophthalmol Vis Sci (2015) 56(3):1517-23. doi: 10.1167/ iovs.14-15030

95. Jiang Y, Wang H, Yu H, Li L, Xu D, Hou S, et al. Two Genetic Variations in the IRF8 region are associated with Behcet's disease in Han Chinese. Sci Rep (2016) 6:19651. doi: 10.1038/srep19651 
96. Chang JH, Hampartzoumian T, Everett B, Lloyd A, McCluskey PJ, Wakefield D. Changes in Toll-like receptor (TLR)-2 and TLR4 expression and function but not polymorphisms are associated with acute anterior uveitis. Invest Ophthalmol Vis Sci (2007) 48(4):1711-7. doi: 10.1167/iovs.060807

97. Triantafilou M, Manukyan M, Mackie A, Morath S, Hartung T, Heine H, et al. Lipoteichoic acid and toll-like receptor 2 internalization and targeting to the Golgi are lipid raft-dependent. J Biol Chem (2004) 279(39):40882-9. doi: 10.1074/jbc.M400466200

98. Nomura F, Akashi S, Sakao Y, Sato S, Kawai T, Matsumoto M, et al. Cutting edge: endotoxin tolerance in mouse peritoneal macrophages correlates with down-regulation of surface toll-like receptor 4 expression. J Immunol (2000) 164(7):3476-9. doi: 10.4049/jimmunol.164.7.3476

99. Rosenbaum JT, McDevitt HO, Guss RB, Egbert PR. Endotoxin-induced uveitis in rats as a model for human disease. Nature (1980) 286(5773):611-3. doi: 10.1038/286611a0

100. Allensworth JJ, Planck SR, Rosenbaum JT, Rosenzweig HL. Investigation of the differential potentials of TLR agonists to elicit uveitis in mice. J Leukoc Biol (2011) 90(6):1159-66. doi: 10.1189/jlb.0511249

101. Fang J, Fang D, Silver PB, Wen F, Li B, Ren X, et al. The role of TLR2, TRL3, TRL4, and TRL9 signaling in the pathogenesis of autoimmune disease in a retinal autoimmunity model. Invest Ophthalmol Vis Sci (2010) 51(6):3092-9. doi: $10.1167 /$ iovs.09-4754

102. Chang JH, McCluskey PJ, Wakefield D. Toll-like receptors in ocular immunity and the immunopathogenesis of inflammatory eye disease. $\mathrm{Br} \mathrm{J}$ Ophthalmol (2006) 90(1):103-8. doi: 10.1136/bjo.2005.072686

103. Wakefield D, Gray P, Chang J, Di Girolamo N, McCluskey P. The role of PAMPs and DAMPs in the pathogenesis of acute and recurrent anterior uveitis. Br J Ophthalmol (2010) 94(3):271-4. doi: 10.1136/bjo.2008.146753

104. Chang JH, McCluskey P, Wakefield D. Expression of toll-like receptor 4 and its associated lipopolysaccharide receptor complex by resident antigenpresenting cells in the human uvea. Invest Ophthalmol Vis Sci (2004) 45 (6):1871-8. doi: 10.1167/iovs.03-1113

105. Brito BE, Zamora DO, Bonnah RA, Pan Y, Planck SR, Rosenbaum JT. Tolllike receptor 4 and CD14 expression in human ciliary body and TLR-4 in human iris endothelial cells. Exp Eye Res (2004) 79(2):203-8. doi: 10.1016/ j.exer.2004.03.012

106. Liversidge J, McKay D, Mullen G, Forrester JV. Retinal pigment epithelial cells modulate lymphocyte function at the blood-retina barrier by autocrine PGE2 and membrane-bound mechanisms. Cell Immunol (1993) 149(2):31530. doi: $10.1006 / \mathrm{cimm} .1993 .1158$

107. Mai K, Chui JJ, Di Girolamo N, McCluskey PJ, Wakefield D. Role of toll-like receptors in human iris pigment epithelial cells and their response to pathogen-associated molecular patterns. I Inflammation (Lond) (2014) 11:20. doi: 10.1186/1476-9255-11-20

108. Dodge IL, Carr MW, Cernadas M, Brenner MB. IL-6 production by pulmonary dendritic cells impedes Th1 immune responses. J Immunol (2003) 170(9):4457-64. doi: 10.4049/jimmunol.170.9.4457

109. Gregerson DS, Heuss ND, Lew KL, McPherson SW, Ferrington DA. Interaction of retinal pigmented epithelial cells and $\mathrm{CD} 4 \mathrm{~T}$ cells leads to T-cell anergy. Invest Ophthalmol Vis Sci (2007) 48(10):4654-63. doi: 10.1167/iovs.07-0286

110. Hsu SM, Mathew R, Taylor AW, Stein-Streilein J. Ex-vivo tolerogenic F4/80 $(+)$ antigen-presenting cells (APC) induce efferent $\mathrm{CD} 8(+)$ regulatory T celldependent suppression of experimental autoimmune uveitis. Clin Exp Immunol (2014) 176(1):37-48. doi: 10.1111/cei.12243

111. Wieczorek M, Abualrous ET, Sticht J, Alvaro-Benito M, Stolzenberg S, Noe F, et al. Major Histocompatibility Complex (MHC) Class I and MHC Class II Proteins: Conformational Plasticity in Antigen Presentation. Front Immunol (2017) 8:292. doi: 10.3389/fimmu.2017.00292

112. Gill T, Asquith M, Brooks SR, Rosenbaum JT, Colbert RA. Effects of HLAB27 on Gut Microbiota in Experimental Spondyloarthritis Implicate an Ecological Model of Dysbiosis. Arthritis Rheumatol (2018) 70(4):555-65. doi: $10.1002 /$ art.40405

113. Baggia S, Lyons JL, Angell E, Barkhuizen A, Han YB, Planck SR, et al. A novel model of bacterially-induced acute anterior uveitis in rats and the lack of effect from HLA-B27 expression. J Invest Med (1997) 45(5):295-301.
114. Rosenbaum JT, Lin P, Asquith M. Does the Microbiome Cause B27-related Acute Anterior Uveitis? Ocul Immunol Inflamm (2016) 24(4):440-4. doi: 10.3109/09273948.2016.1142574

115. Misiuk-Hojlo M, Miedzybrodzki R, Grzybowski A, Lugowski C, Niedziela T, Turno-Krecicka A, et al. Elevated levels of anti-endotoxin antibodies in patients with bilateral idiopathic acute anterior uveitis. Acta Ophthalmol (2011) 89(3):e283-8. doi: 10.1111/j.1755-3768.2010.01969.x

116. Curnow SJ, Murray PI. Inflammatory mediators of uveitis: cytokines and chemokines. Curr Opin Ophthalmol (2006) 17(6):532-7. doi: 10.1097/ ICU.0b013e32801094b5

117. Mirshahi A, Hoehn R, Lorenz K, Kramann C, Baatz H. Anti-tumor necrosis factor alpha for retinal diseases: current knowledge and future concepts. J Ophthalmic Vis Res (2012) 7(1):39-44.

118. Bazzoni F, Beutler B. The tumor necrosis factor ligand and receptor families. N Engl J Med (1996) 334(26):1717-25. doi: 10.1056/NEJM199606273342607

119. Cid MC, Kleinman HK, Grant DS, Schnaper HW, Fauci AS, Hoffman GS. Estradiol enhances leukocyte binding to tumor necrosis factor (TNF)-stimulated endothelial cells via an increase in TNF-induced adhesion molecules E-selectin, intercellular adhesion molecule type 1 , and vascular cell adhesion molecule type 1. J Clin Invest (1994) 93(1):17-25. doi: 10.1172/JCI116941

120. Deshmukh D, Chakrabarti M, Jayasudha R, Hasnat Ali M, Tyagi M, Sharma $\mathrm{S}$, et al. Elevated cytokine levels in vitreous as biomarkers of disease severity in infectious endophthalmitis. PloS One (2018) 13(10):e0205292. doi: 10.1371/journal.pone.0205292

121. Ramadan RT, Moyer AL, Callegan MC. A role for tumor necrosis factoralpha in experimental Bacillus cereus endophthalmitis pathogenesis. Invest Ophthalmol Vis Sci (2008) 49(10):4482-9. doi: 10.1167/iovs.08-2085

122. Parkunan SM, Randall CB, Astley RA, Furtado GC, Lira SA, Callegan MC. CXCL1, but not IL-6, significantly impacts intraocular inflammation during infection. J Leukoc Biol (2016) 100(5):1125-34. doi: 10.1189/jlb.3A0416-173R

123. Jabs DA. Immunosuppression for the Uveitides. Ophthalmology (2018) 125 (2):193-202. doi: 10.1016/j.ophtha.2017.08.007

124. Pleyer U, Pohlmann D, Kardes E, Poddubnyy D, Rademacher J. Emerging drugs for the treatment of noninfectious uveitis. Expert Opin Emerg Drugs (2019) 24(3):173-90. doi: 10.1080/14728214.2019.1663823

125. Ouyang J, Isnard S, Lin J, Fombuena B, Peng X, Nair Parvathy S, et al. Treating From the Inside Out: Relevance of Fecal Microbiota Transplantation to Counteract Gut Damage in GVHD and HIV Infection. Front Med (Lausanne) (2020) 7:421. doi: 10.3389/fmed.2020.00421

126. Mishima Y, Sartor RB. Manipulating resident microbiota to enhance regulatory immune function to treat inflammatory bowel diseases. J Gastroenterol (2020) 55(1):4-14. doi: 10.1007/s00535-019-01618-1

127. Xu C, Lee SK, Zhang D, Frenette PS. The Gut Microbiome Regulates Psychological-Stress-Induced Inflammation. Immunity (2020) 53(2):41728 e4. doi: 10.1016/j.immuni.2020.06.025

128. Suriguga S, Luangmonkong T, Mutsaers HAM, Groothuis GMM, Olinga P. Host microbiota dictates the proinflammatory impact of LPS in the murine liver. Toxicol In Vitro (2020) 67:104920. doi: 10.1016/j.tiv.2020.104920

129. Zhou J, Yang J, Dai M, Lin D, Zhang R, Liu H, et al. A combination of inhibiting microglia activity and remodeling gut microenvironment suppresses the development and progression of experimental autoimmune uveitis. Biochem Pharmacol (2020) 180:114108. doi: 10.1016/j.bcp.2020.114108

130. Kuczma MP, Szurek EA, Cebula A, Chassaing B, Jung YJ, Kang SM, et al. Commensal epitopes drive differentiation of colonic Tregs. Sci Adv (2020) 6 (16):eaaz3186. doi: 10.1126/sciadv.aaz3186

Conflict of Interest: The authors declare that the research was conducted in the absence of any commercial or financial relationships that could be construed as a potential conflict of interest.

Copyright $\odot 2020 \mathrm{Li}$, Yi and Wei. This is an open-access article distributed under the terms of the Creative Commons Attribution License (CC BY). The use, distribution or reproduction in other forums is permitted, provided the original author(s) and the copyright owner(s) are credited and that the original publication in this journal is cited, in accordance with accepted academic practice. No use, distribution or reproduction is permitted which does not comply with these terms. 